\title{
An early start of Coup-TFII promotes $\gamma$-globin gene expression in adult erythroid cells
}

\author{
Stefania Bottardi ${ }^{1}$ and Eric Milot ${ }^{1,2}$
}

\author{
${ }^{1}$ Maisonneuve Rosemont Hospital Research Center, CIUSSS Est de l'Île de Montréal, Montréal, and 'Department of Medicine, \\ University of Montreal, Montréal, Québec, Canada
}

E-mail: ERIC MILOT - e.milot.1@umontreal.ca

doi:10.3324/haematol.2020.266791

M utations of the human $\beta$-globin gene can affect the quantity or quality of the $\beta$-globin subunit and result in $\beta$-thalassemia or sickle cell anemia (respectively). These disorders can be regrouped under the designation of $\beta$-hemoglobinopathies and are the most frequent monogenic inherited diseases worldwide. ${ }^{1}$ The severity of $\beta$-hemoglobinopathies is strongly related to the nature of the mutation. Allogeneic hematopoietic stem cell transplantation is the most established cure for severe forms of $\beta$-hemoglobinopathies. However, like other clinical approaches, including gene therapy, which are used to correct this group of genetic diseases, allogeneic hematopoietic stem cell transplantation is not without risk and can be associated with complications. ${ }^{2}$

The developmental switching from $\gamma$ - to $\beta$-globin gene expression occurs around birth and results in the formation of the adult form of hemoglobin, which is primarily composed of $\beta$ and $\alpha$-globin chains ( $\mathrm{HbA}, \alpha 2 \beta 2)$. $\mathrm{HbA}$ gradually replaces the fetal hemoglobin $(\mathrm{HbF}, \alpha 2 \gamma 2)$ and hence, the developmental globin switching represents the genetic basis of $\mathrm{HbF}$ decline, which will drop to less than $1 \%$ within a few months of birth (by 6 months of age). ${ }^{3}$ However, a condition known as hereditary persistence of fetal hemoglobin (HPFH) is characterized by the maintenance of $\mathrm{HbF}$ at levels as high as $10 \%$ to $40 \%$ of total hemoglobin in adult blood. ${ }^{4}$ This condition is asymptomatic and can compensate for $\beta$-globin gene mutations that otherwise promote $\beta$-hemoglobinopathies. Indeed, increased $\mathrm{HbF}$ levels in adult blood cells is beneficial to patients with mutations affecting the quantity or quality of the $\beta$-globin chains. Thus, a substantial number of studies have been performed to determine how the reactivation of $\gamma$-globin genes could be efficiently reproduced in adult blood cells. However, the complexity of gene regulation at this multigenic locus and the absence of a known specific activator of the $\gamma$-globin genes that would not simultaneously increase the expression of the $\beta$-globin gene have delayed this achievement.

To modulate the expression levels of human $\beta$-type globin genes, the influence of multiple control elements and different mechanisms of gene regulation have to be considered. Furthermore, tissue- and development-specific expression of $\beta$-type globin genes relies on a complex network of transcription factors, cofactors and regulatory complexes. ${ }^{5-7}$ For instance, in addition to binding gene regulatory regions, different transcription factors favor longrange interactions between promoters and distal regulatory elements of the locus in order to induce high levels of globin gene expression. ${ }^{8}$ Nonetheless, while many different transcriptional activators can influence these longrange interactions in the $\beta$-globin locus, it has been demonstrated that one engineered transcriptional regulator can be sufficient to induce these structures and reacti- vate $\gamma$-globin genes in adult erythroid cells. ${ }^{9}$ Another example of the complex regulation of globin genes is the number of transcription factors and complexes involved in $\gamma$-globin gene repression in adult erythroid cells. Indeed, although BCL11A is instrumental in the repression of $\gamma$ globin genes at an adult stage of development, ${ }^{10,11}$ the mutation of many different transcription factors and cofactors results in the partial reactivation of $\gamma$-globin genes. ${ }^{6}$ Thus, even if discoveries such as the dominant effect of BCL11A on $\gamma$-globin gene repression are promising for the development of novel therapies to fight $\beta$ hemoglobinopathies, the main objective of different studies remains the identification of a transcriptional activator capable of reactivating the $\gamma$-globin genes in adult erythroid cells. A specific activator of the human $\beta$-globin gene was identified in KLF1 (EKLF), ${ }^{12}$ but until now such a transcriptional factor or cofactor specifically involved in the $\gamma$-globin gene activation was lacking. Importantly, in this issue of Haematologica, Fugazza et al. report that CoupTFII, which was originally considered to be a $\gamma$-globin gene repressor, is a specific transcriptional activator of $\varepsilon$ and $\gamma$-globin genes. ${ }^{13}$

Fugazza et al. report that, when expressed in adult erythroid cells of healthy donors or thalassemic patients carrying the Sardinian $\beta^{0} 39$ mutation ( $\beta^{0} 39$-Thal), Coup-TFII can reactivate $\gamma$-globin gene expression. ${ }^{13}$ Their identification of Coup-TFII as a specific activator of $\gamma$-globin genes that can enhance $\mathrm{HbF}$ production in adult red blood cells brings hope, and increases the therapeutic possibilities to fight $\beta$-hemoglobinopathies.

The Coup-TFII (NR2F2/ARP-1) orphan nuclear receptor was initially identified as a component of the $\varepsilon$ - and $\gamma$-globin gene-regulating complex NF-E3. It was proposed to be a positive regulator of the $\varepsilon$-globin gene but a negative regulator of $\gamma$-globin genes. ${ }^{14}$ Further investigation indicated that NF-E3/Coup-TFII can interfere with the recruitment of different transcriptional regulators to $\varepsilon$ - and $\gamma$-globin promoters, and unveiled conflicting results that could imply its involvement in the transcriptional activation of $\gamma$-globin genes. ${ }^{15}$ However, detailed molecular analysis of the precise effect of Coup-TFII on globin gene regulation during development has been complicated by the fact that it binds different regulatory regions of the $\beta$-globin locus and because Coup-TFII knockout is lethal at the embryonic stage of mouse development.

To study the importance of the transcription factor Coup-TFII in the regulation of embryonic and fetal globin genes, Fugazza et al. used transgenic mice carrying the human $\beta$-globin locus, a $\beta$-K562 human cell line and human blood cells from healthy or $\beta^{0} 39$-Thal donors. ${ }^{13}$ In mice, they found that Coup-TFII expression occurs at the same developmental stage as endogenous murine or transgenic human embryonic/fetal globin genes and, like the 
embryonic/fetal globin genes, Coup-TFII expression extinguishes at embryonic day 12.5. However, they showed that only a small percentage of erythroid cells are characterized by the simultaneous expression of Coup-TFII and mouse or human embryonic/fetal globin genes. Their results indicate that Coup-TFII expression is initiated in the erythroid-myeloid precursor cells and precedes $\gamma$-globin gene transcription during erythroid cell maturation, thus suggesting that the effect of Coup-TFII precedes the transcriptional activation of $\varepsilon$ - and $\gamma$-globin genes during erythroid cell differentiation/formation. Interestingly, in hematopoietic progenitor cells the human $\beta$-like globin genes are 'primed' for their subsequent transcriptional activation in erythroid cells. ${ }^{16-18} \mathrm{~A}$ few transcription factors have been reported to favor globin gene priming. 19,20 Thus, Coup-TFII might also be involved in globin gene priming and, thereby, promote the specific activation of $\varepsilon$ - and $\gamma$ globin genes.

The effect of Coup-TFII expression was also tested in adult erythroid progenitor cells obtained from healthy donors and $\beta^{0} 39$-Thal patients. As in the transgenic mouse model carrying the human $\beta$-globin locus, Coup-TFII expression was sufficient to reactivate the $\gamma$-globin genes in human adult erythroid cells. Furthermore, as indicated by the fold change in gene transcription, the effect of Coup-TFII was specific for $\gamma$ - but not $\beta$-globin gene expression. Therefore, the results presented by Fugazza et al. indicate that the induction of Coup-TFII expression in adult erythroid cells could be beneficial for the treatment of patients with $\beta$-hemoglobinopathies.

To further characterize the molecular aspects linked to Coup-TFII-related activation of $\gamma$-globin genes, Coup-TFII knockout or overexpression was engineered in a human model cell line, $\beta$-K562 cells. Genome-wide analysis of Coup-TFII chromatin binding performed by chromatin immunoprecipitation (ChIP)-sequencing suggested that Coup-TFII is frequently recruited to genes/loci associated with hematologic diseases. This analysis identified significant peaks of Coup-TFII binding within the $\beta$-globin locus control region hypersensitive sites 2 (HS2), HS3, HS4, and the $\gamma-\delta$ intergenic region. Accordingly, it was found that Coup-TFII overexpression increases the longrange interaction between the locus control region and this $\gamma-\delta$ intergenic region. Overall the analyses performed in $\beta$-K562 cells indicate that Coup-TFII binds to regulatory regions and influences the organization of the human $\beta$ globin locus. Furthermore, the ChIP-sequencing analysis and the finding that Coup-TFII peaks frequently overlap with GATA consensus binding sequences, led the authors to propose the participation of Coup-TFII in the erythropoietic program.

Considered collectively, the results presented by Fugazza et al. elucidate the role of Coup-TFII in the regulation of $\varepsilon$ - and $\gamma$-globin genes during development. ${ }^{13}$ Unlike previously reported findings, these results reveal that Coup-TFII favors the transcriptional activation of $\gamma$ globin genes. Furthermore, they indicate that, when expressed in adult erythroid progenitor cells, Coup-TFI preferentially reactivate the expression of $\gamma$ - over $\beta$-globin genes, thus providing new possibilities for the induction of $\gamma$-globin gene expression in adult erythroid cells.

\section{Disclosures}

No conflicts of interest to disclose.

\section{Contributions}

$S B$ and EM wrote the manuscript.

\section{Funding}

This work was supported by a grant from the Canadian Institute of Health Research (CIHR: MOP133420) to EM.

\section{References}

1. Weatherall DJ. Phenotype-genotype relationships in monogenic disease: lessons from the thalassaemias. Nat Rev Genet. 2001;2(4):245255.

2. Payen E, Leboulch P. Advances in stem cell transplantation and gene therapy in the beta-hemoglobinopathies. Hematology Am Soc Hematol Educ Program. 2012;2012:276-283.

3. Stamatoyannopoulos G. Control of globin gene expression during development and erythroid differentiation. Exp Hematol. 2005;33(3):259-271.

4. Menzel S, Thein SL. Genetic architecture of hemoglobin F control. Curr Opin Hematol. 2009;16(3):179-186.

5. Johnson KD, Grass JA, Boyer ME, et al. Cooperative activities of hematopoietic regulators recruit RNA polymerase II to a tissue-specific chromatin domain. Proc Natl Acad Sci U S A. 2002;99(18): 11760-11765.

6. Andrieu-Soler C, Soler E. When basic science reaches into rational therapeutic design: from historical to novel leads for the treatment of beta-globinopathies. Curr Opin Hematol. 2020;27(3):141-148.

7. Rodriguez P, Bonte E, Krijgsveld J, et al. GATA-1 forms distinct activating and repressive complexes in erythroid cells. EMBO J. 2005;24(13):2354-2366.

8. Noordermeer D, de Laat W. Joining the loops: beta-globin gene regulation. IUBMB Life. 2008;60(12):824-833.

9. Deng W, Rupon JW, Krivega I, et al. Reactivation of developmentally silenced globin genes by forced chromatin looping. Cell. 2014;158(4):849-860.

10. Liu N, Hargreaves VV, Zhu Q, et al. Direct promoter repression by BCL11A controls the fetal to adult hemoglobin switch. Cell. 2018;173(2):430-442.e17

11. Sankaran VG, Orkin SH. The switch from fetal to adult hemoglobin Cold Spring Harb Perspect Med. 2013;3(1):a011643.

12. Siatecka M, Bieker JJ. The multifunctional role of EKLF/KLF1 during erythropoiesis. Blood. 2011;118(8):2044-2054.

13. Fugazza C, Barbarani G, Elangovan S, et al. The Coup-TFII orphan nuclear receptor is an activator of the gamma-globin gene. Haematologica. 2021;106(2):474-482.

14. Ronchi AE, Bottardi S, Mazzucchelli C, Ottolenghi S, Santoro C. Differential binding of the NFE3 and CP1/NFY transcription factors to the human gamma- and epsilon-globin CCAAT boxes. J Biol Chem. 1995;270(37):21934-21941.

15. Liberati C, Cera MR, Secco P, et al. Cooperation and competition between the binding of COUP-TFII and NF-Y on human epsilonand gamma-globin gene promoters. J Biol Chem. 2001;276(45): 41700-41709.

16. Papayannopoulou T, Brice M, Stamatoyannopoulos G. Hemoglobin F synthesis in vitro: evidence for control at the level of primitive erythroid stem cells. Proc Natl Acad Sci U S A. 1977;74(7):2923-2927.

17. Papayannopoulou TH, Brice M, Stamatoyannopoulos G. Stimulation of fetal hemoglobin synthesis in bone marrow cultures from adult individuals. Proc Natl Acad Sci U S A. 1976;73(6):2033-2037.

18. Bottardi S, Aumont A, Grosveld F, Milot E. Developmental stagespecific epigenetic control of human beta-globin gene expression is potentiated in hematopoietic progenitor cells prior to their transcriptional activation. Blood. 2003;102(12):3989-3997.

19. Bottardi S, Ross J, Pierre-Charles N, Blank V, Milot E. Lineage-specific activators affect beta-globin locus chromatin in multipotent hematopoietic progenitors. EMBO J. 2006;25(15):3586-3595.

20. Dulmovits BM, Appiah-Kubi AO, Papoin J, et al. Pomalidomide reverses gamma-globin silencing through the transcriptional reprogramming of adult hematopoietic progenitors. Blood. 2016;127(11): 1481-1492. 